\title{
A Prospective Study of the Effect of 12 Months Treatment on Serum Lipids and Apolipoproteins A-I and B in Type 2 (Non-Insulin-Dependent) Diabetes
}

\author{
K. G. Taylor, ${ }^{1}$ W. G. John, ${ }^{2}$ K. A. Matthews ${ }^{3}$ and A. D. Wright ${ }^{4}$ \\ ${ }^{1}$ Dudley Road Hospital, Departments of ${ }^{2}$ Clinical Chemistry and ${ }^{3}$ Statistics, Queen Elizabeth Hospital and ${ }^{4}$ General Hospital, Birmingham, UK
}

\begin{abstract}
Summary. Serum high density lipoprotein cholesterol, total cholesterol, triglyceride and apolipoproteins A-I and B were studied at diagnosis and after 12 months conventional treatment in a group of Type 2 (non-insulin-dependent) diabetic patients. No significant deleterious effect on serum lipids and apolipoproteins was seen in any of the subgroups during the treatment period, although in the overall group there was a significant increase in serum total cholesterol in females. Serum high density lipoprotein cholesterol increased signifi-
\end{abstract}

cantly in obese males treated with calorie restriction alone. There was a significant increase in serum apolipoprotein A-I in obese females treated with calorie restriction and metformin and in non-obese females treated with carbohydrate restriction and glibenclamide.

Key words: Type 2 diabetes, prospective study, diet, metformin, glibenclamide, HDL-cholesterol, total cholesterol, triglyceride, apolipoproteins A-I and B.
In the United Kingdom previous conventional treatment for diabetes developing in middle or later life and not requiring insulin has in the first instance been diet with reduced carbohydrate intake and then later addition of a sulphonylurea drug or metformin if diet alone is unsuccessful. In spite of lowering blood glucose and abolishing symptoms, studies have shown that these patients suffer considerable morbidity and mortality from macrovascular disease [1, 2]. Vascular disease could result from persistent elevation of blood lipids although blood glucose levels are controlled [3, 4]; alternatively, oral therapy itself may have a deleterious effect on blood lipids. A study comparing patients with diabetes receiving diet and placebo, diet and tolbutamide and diet and insulin showed a higher cardiovascular mortality among those receiving diet and tolbutamide [5]. A retrospective study showed lower high-density lipoprotein (HDL) cholesterol levels in patients receiving diet and sulphonylurea therapy than those on diet alone [6]. HDL may protect against the subsequent development of atherosclerosis [7].

Concentrations of serum total cholesterol, triglyceride, HDL-cholesterol and apolipoproteins A-I and B were measured in a group of Type 2 (non-insulin-dependent) diabetic patients at diagnosis and following 1 year of treatment. Obese subjects were treated with calorie restriction or with calorie restriction and metformin when diet alone proved inadequate. Non-obese subjects were treated by carbohydrate restriction or carbohydrate restriction and glibenclamide if diet alone failed. Base line characteristics of this group of patients at diagnosis have been reported previously [8].

\section{Patients and Methods}

\section{Patients}

One hundred and thirty-one consecutive patients ( 71 males, mean age 51 years and 60 females, mean age 52 years) newly presenting at our diabetic clinic were selected if they were ambulant, $<65$ years of age and had a random venous blood glucose $>10.0 \mathrm{mmol} / \mathrm{l}$ and a fasting blood glucose $>7.0 \mathrm{mmol} / \mathrm{l}$.

Fasting blood for measurement of blood glucose, glycosylated haemogiobin $\left(\mathrm{HbA}_{1}\right)$, serum total cholesterol, triglyceride, HDL-cholesterol and apolipoproteins A-I and B was withdrawn at diagnosis and after 12 months treatment. Patients receiving drugs known to affect lipid metabolism were excluded as were those with any biochemical evidence of renal or hepatic impairment demonstrated by an elevated blood urea or abnormal liver function tests. Non-obese was defined as $<120 \%$ ideal body weight with ideal weight derived from the Metropolitan Life Insurance Company Tables [9]. Non-obese patients were given diets in which carbohydrate was restricted but fat and protein were unrestricted. Obese patients received instructions on calorie restriction based on an assessment of their daily activities with restriction of fat and all carbohydrate intake so that $42 \%$ of calories were obtained from carbohydrate, $40 \%$ from fat and $18 \%$ from protein.

Diet was used as first-line treatment and oral agents used only when diet failed after a reasonable period of time (not $<1$ month and usually 3 months). The aims of treatment were to abolish symptoms, 
Table 1. Clinical and biochemical data on patients with Type 2 diabetes at presentation and after 1 year of treatment

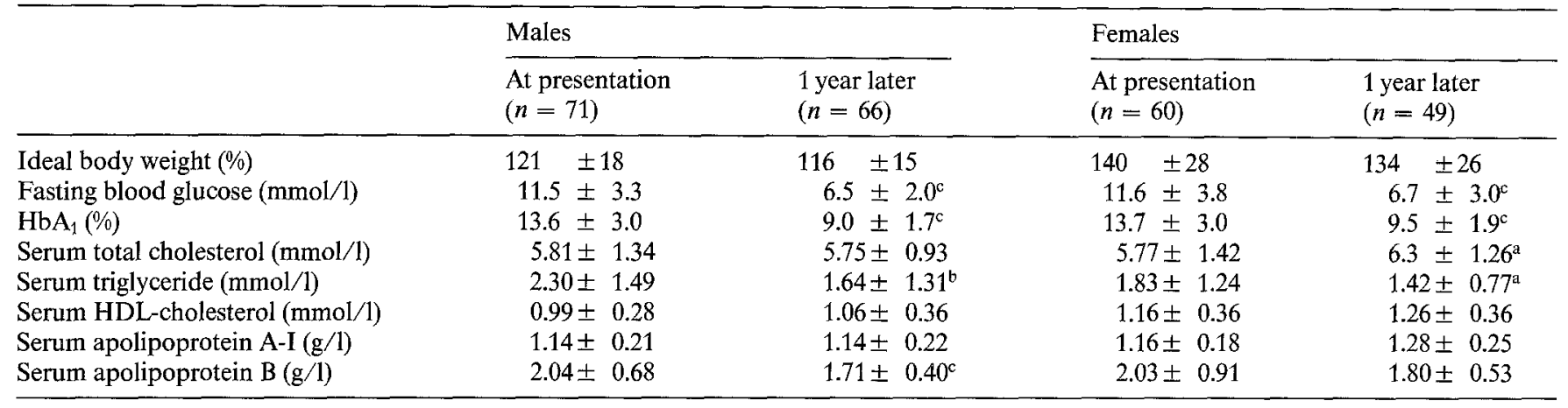

Results expressed as mean $\pm \mathrm{SD} ;{ }^{\mathrm{a}} p<0.05 \quad{ }^{\mathrm{b}} p<0.01 \quad{ }^{\mathrm{c}} p<0.001$

Table 2. The effect of diet alone for 1 year in patients with Type 2 diabetes

Calorie restriction in obese patients

\begin{tabular}{|c|c|c|c|c|c|c|}
\hline \multirow[b]{3}{*}{ Ideal body weight $(\%)$} & \multicolumn{2}{|l|}{ Males $(n=25)$} & \multicolumn{2}{|l|}{ Females $(n=18)$} & \multicolumn{2}{|l|}{ Males $(n=7)$} \\
\hline & At presentation & 1 year later & At presentation & 1 year later & At presentation & 1 year later \\
\hline & \pm 17 & $118 \pm 11^{\mathrm{c}}$ & $151 \pm 23$ & $\pm 24^{c}$ & $114 \pm 5$ & $110 \pm 6^{a}$ \\
\hline $\mathrm{HbA}_{1}(\%)$ & $12.3 \pm 2.6$ & $8.5 \pm 1.7^{\mathrm{c}}$ & $12.7 \pm 3.7$ & $8.6 \pm 2.1^{\mathrm{b}}$ & $12.1 \pm 1.8$ & $8.9 \pm 0.7^{\mathrm{a}}$ \\
\hline Serum total cholesterol $(\mathrm{mmol} / \mathrm{l})$ & $5.72 \pm 1.17$ & $5.48 \pm 0.95$ & $5.69 \pm 1.57$ & $6.43 \pm 1.14$ & $5.48 \pm 1.79$ & $6.02 \pm 1.24$ \\
\hline Serum triglyceride $(\mathrm{mmol} / \mathrm{l})$ & $2.00 \pm 0.81$ & $1.28 \pm 0.75^{c}$ & $2.20 \pm 1.50$ & $1.99 \pm 1.56$ & $2.51 \pm 1.81$ & $2.12 \pm 1.53$ \\
\hline Serum apolipoprotein $B(g / 1)$ & $1.82 \pm 0.65$ & $1.63 \pm 0.39$ & $2.29 \pm 0.71$ & $2.00 \pm 0.42$ & $2.04 \pm 0.55$ & $1.76 \pm 0.51$ \\
\hline
\end{tabular}

Results expressed as mean $\pm \mathrm{SD} ;{ }^{\mathrm{a}} p<0.05 \quad{ }^{\mathrm{b}} p<0.01 \quad{ }^{\mathrm{c}} p<0.001$

achieve urine tests mainly negative for glucose and reduce the fasting blood glucose to $<7.0 \mathrm{mmol} / \mathrm{l}$. Two drugs were used: glibenclamide for the non-obese in doses ranging from 2.5 to $15 \mathrm{mg} /$ day, and metformin for the obese at a dose of $500 \mathrm{mg}$ three times daily. Non-obese patients allocated to carbohydrate restriction and glibenclamide were transferred to insulin therapy if hyperglycaemia persisted on a maximal dose of glibenclamide. Obese patients not responding to calorie restriction and metformin, additionally received glibenclamide. The four treatment groups of patients described in this study are: (1) calorie restriction, (2) calorie restriction with metformin, (3) carbohydrate restriction and (4) carbohydrate restriction with glibenclamide.

Patients were regularly supervised in a special clinic so that all blood samples were taken while fasting, and lipid determinations were repeated at 3 monthly intervals over the 12 month period.

There was incomplete data on 16 patients at 1-year follow-up. Nine non-obese females on carbohydrate restriction and glibenclamide required insulin therapy for hyperglycaemia during the first year of treatment. Two obese females who were inadequately controlled on diet and metformin subsequently received glibenclamide as well.

\section{Assays}

Serum triglyceride was determined using an automated enzymic method (Boehringer Product No.12603917) [10] and serum cholesterol also using an automated enzymic method (Boehringer Product No. 187313) [11]. HDL-cholesterol was determined after precipitation of very-low-density and low-density lipoproteins (VLDL and LDL) using sodium phosphotungstate at neutral $\mathrm{pH}$ in the presence of magnesium ions $[12,13]$. The intra- and inter-assay coefficients of variation for serum HDL-cholesterol were $1.2 \%$ and $2 \%$, respectively. To ensure completeness of precipitation of VLDL and LDL, representative HDL-containing supernatant fluids were checked to see they did not contain apolipoprotein B. Apolipoproteins A-I and B were measured by rocket immuno-electrophoresis on whole serum using highly specific antisera [14]. Intra- and inter-assay coefficients of variation for serum apolipoproteins were $<10 \%$. $\mathrm{HbA}_{1}$ was determined using a temperature-controlled modification of a microcolumn method [15].

\section{Statistical Analyses}

Results are presented as mean $\pm \mathrm{SD}$. The data were analysed using a statistical computer package implemented on the University of Birmingham's ICL 1906A computer. Comparisons between means were made with Student's t-test, unpaired for Table 1 and paired for Tables 2 and 3, after it had been shown that the distribution of the data was reasonably normal.

\section{Results}

Table 1 shows the 1-year follow-up results on the original group of 131 patients. In both sexes there was an insignificant weight loss but significant improvement of hyperglycaemia and serum triglyceride levels. In the males serum total cholesterol, HDL-cholesterol and apolipoprotein A-I were not significantly changed, while apolipoprotein B decreased $(p<0.001)$. In the females serum total cholesterol increased $(p<0.05)$, while apolipoproteins A-I and B were not significantly changed. 
Table 3. The effect of diet and drug treatment for 1 year in patients with Type 2 diabetes

\begin{tabular}{|c|c|c|c|c|c|c|c|c|}
\hline \multirow[b]{4}{*}{ Ideal body weight (\%) } & \multicolumn{4}{|c|}{ Calorie restriction and metformin in obese patients } & \multicolumn{4}{|c|}{ Carbohydrate restriction and glibenclamide in non-obese patients } \\
\hline & \multicolumn{2}{|l|}{ Males $(n=10)$} & \multicolumn{2}{|l|}{ Females $(n=13)$} & \multicolumn{2}{|l|}{ Males $(n=24)$} & \multicolumn{2}{|l|}{ Females $(n=7)$} \\
\hline & At presentation & 1 year later & At presentation & 1 year later & At presentation & 1 year later & At presentation & 1 year later \\
\hline & \pm 24 & $\pm 22^{\mathrm{a}}$ & $154 \pm 18$ & $\pm 23^{\mathrm{b}}$ & \pm 15 & \pm 12 & \pm 11 & 112 \\
\hline $\begin{array}{l}\text { Fasting blood glucose } \\
(\mathrm{mmol} / \mathrm{l})\end{array}$ & $11.1 \pm 3.6$ & $6.8 \pm 2.9^{\mathrm{a}}$ & $12.5 \pm 3.1$ & $6.3 \pm 3.0^{c}$ & $12.2 \pm 3.3$ & $6.7 \pm 2.0^{c}$ & $13.4 \pm 2.3$ & $6.4 \pm 2.2^{b}$ \\
\hline $\mathrm{HbA}_{1}(\%)$ & $13.1 \pm 2.4$ & $8.9 \pm 0.6^{\mathrm{a}}$ & $14.8 \pm 2.0$ & $9.5 \pm 1.28^{\mathrm{b}}$ & $14.2 \pm 3.8$ & $8.6 \pm 1.4$ & $15.3 \pm 0.8$ & $8.9 \pm 1.7^{\mathrm{a}}$ \\
\hline $\begin{array}{l}\text { Serum total cholesterol } \\
(\mathrm{mmol} / \mathrm{l})\end{array}$ & $6.21 \pm 0.81$ & $5.66 \pm 0.83^{\mathrm{a}}$ & $6.41 \pm 1.62$ & $6.47 \pm 1.58$ & $6.05 \pm 1.44$ & $5.78 \pm 0.96$ & $6.53 \pm 0.69$ & $6.97 \pm 0.74$ \\
\hline Serum triglyceride $(\mathrm{mmol} / \mathrm{l})$ & $2.42 \pm 1.12$ & $1.48 \pm 0.66^{b}$ & $2.25 \pm 1.83$ & $1.58 \pm 1.08^{\mathrm{a}}$ & $2.38 \pm 1.96$ & $1.80 \pm 1.76$ & $1.30 \pm 0.69$ & $1.04 \pm 0.52$ \\
\hline $\begin{array}{l}\text { Serum HDL-cholesterol } \\
(\mathrm{mmol} / \mathrm{l})\end{array}$ & $0.94 \pm 0.18$ & $0.95 \pm 0.12$ & $1.15 \pm 0.40$ & $1.25 \pm 0.33$ & $1.07 \pm 0.21$ & $1.07 \pm 0.30$ & $1.39 \pm 0.51$ & $1.48 \pm 0.45$ \\
\hline Serum apolipoprotein A-I $(g / l)$ & $1.19 \pm 0.23$ & $1.06 \pm 0.18$ & $1.18 \pm 0.21$ & $1.30 \pm 0.19^{\mathrm{a}}$ & $1.17 \pm 0.19$ & $1.16 \pm 0.16$ & $1.16 \pm 0.29$ & $1.44 \pm 0.21^{\mathrm{b}}$ \\
\hline Serum apolipoprotein B (g/l) & $2.22 \pm 0.58$ & $1.68 \pm 0.36^{\mathrm{b}}$ & $2.65 \pm 1.39$ & $1.94 \pm 0.79$ & $2.08 \pm 0.82$ & $1.76 \pm 0.50^{\mathrm{a}}$ & $1.79 \pm 0.47$ & $1.66 \pm 0.25$ \\
\hline
\end{tabular}

Male patients both in the group treated with calorie restriction alone and the group treated with calorie restriction and metformin were less obese than the females in these groups (Tables 2 and 3). Both male and female groups lost weight on calorie restriction $(p<$ 0.001 ) and their fasting blood glucose and $\mathrm{HbA}_{1}$ levels were satisfactorily reduced. Serum triglyceride levels decreased and HDL-cholesterol levels increased in men treated with calorie restriction alone $(p<0.001$ and $<0.05$, respectively). These changes were not seen in females treated with calorie restriction alone.

Treatment for 1 year with calorie restriction and metformin led to a reduction in serum total cholesterol and apolipoprotein B in males $(p<0.05$ and $<0.01$, respectively) and a non-significant reduction in apolipoprotein B in females. Serum triglyceride levels decreased in both sexes but more significantly in males $(p<0.01)$. However, HDL-cholesterol was increased in females and apolipoprotein A-I was significantly increased $(p<0.05)$.

The group of males treated with carbohydrate restriction lost weight and satisfactory diabetic control was achieved, but there were no significant changes in serum lipids and apolipoproteins A-I and B (Table 2).

In patients treated with carbohydrate restriction and glibenclamide (Table 3), there were no significant changes in total cholesterol, triglyceride, HDL-cholesterol and apolipoprotein A-I levels in males, but a significant reduction in apolipoprotein B $(p<0.05)$. In the smaller group of females, HDL-cholesterol was increased and apolipoprotein A-I was significantly increased $(p<0.01)$.

\section{Discussion}

None of the treatment regimes had a significantly deleterious effect on serum lipids and apolipoproteins, although in all female subgroups (calorie restriction, calorie restriction plus metformin and carbohydrate restriction plus glibenclamide), there was a trend for serum to- tal cholesterol to rise and this is reflected in the overall group where there was a significant increase in serum total cholesterol. This suggests that the females may have changed to a higher fat diet even when they were advised on a particular fat intake, as in the calorie-restricted diet. Those on carbohydrate restriction were not advised about fat intake and may well have increased it.

The data on calorie restriction show that a group of overweight patients can adhere to a calorie-controlled diet and lose weight not just in the short-term but over a period of 12 months. Both sexes benefited in terms of reduced fasting blood glucose and $\mathrm{HbA}_{1}$ levels, and the males showed a significant reduction in triglyceride levels with a reciprocal change in HDL-cholesterol, but these changes were not seen in the females similarly treated. A possible explanation is that the females were more obese than the males at the commencement of the study (151-128\% ideal body weight) and although they lost more weight than the males, they were still considerably more obese after 1 year (137-118\% ideal body weight). Alternatively, these findings are in keeping with observations we made on a non-diabetic population showing a significant positive correlation between serum triglyceride and obesity expressed as percentage ideal body weight in males but not in females [16]. We also showed that there was no relationship between obesity and serum HDL-cholesterol or apolipoprotein A-I levels in either sex. HDL-cholesterol levels may have increased in the male diabetic patients because of the established inverse relationship between serum triglyceride and HDL-cholesterol.

The males and females treated with metformin and calorie restriction were more obese than those on calorie restriction alone and although they lost weight on treatment for 1 year they remained markedly obese (128 and $147 \%$ ideal body weight, respectively). Nevertheless there were significant reductions in total cholesterol, triglyceride and apolipoprotein B in the male group, but serum HDL-cholesterol levels remained unchanged despite the advantageous effect seen in males on calorie restriction alone. Surprisingly, females receiving met- 
formin differed from the males in showing an increase in HDL-cholesterol with a significant increase in apolipoprotein A-I. Indeed metformin seems to have reversed the male/female difference on HDL-cholesterol seen with calorie restriction alone.

In many diabetic clinics carbohydrate restriction is the initial treatment of choice for the non-obese Type 2 diabetic patient. In our group of seven males treated in this way, the serum cholesterol increased but not significantly; however, the numbers were small. An increase in total cholesterol would not be surprising as overall calories were not restricted and so the reduction in carbohydrate intake may have been compensated by an increase in fat consumption. The reasons for the small numbers and the absence of females in this treatment group are that firstly, $60 \%$ of our randomly selected patients were obese and therefore entered the calorie restricted group. Secondly, because of hyperglycaemia many initially in this group progressed at an early stage to carbohydrate restriction plus glibenclamide and in some cases to insulin with maximal doses of glibenclamide having proved ineffective.

An interesting finding in females was the beneficial effect of carbohydrate restriction and glibenclamide on apolipoprotein A-I and HDL-cholesterol, the effect on the former being significant. It is puzzling at first sight that this effect should not have been seen in the men. Neither sex showed $>1 \%$ change in ideal body weight and diabetic control improved similarly as shown by the fasting blood glucose and $\mathrm{HbA}_{1}$ levels. However, the males were more hypertriglyceridaemic than the females both before and after treatment and this may offer some explanation for the different response of apolipoprotein A-I and HDL-cholesterol to the same treatment in males and females.

We have shown previously that non-insulin-dependent diabetic patients have reduced levels of HDLcholesterol at diagnosis and that this is more pronounced with concomitant hypertriglyceridaemia [8]. None of the treatments discussed have improved HDLcholesterol levels significantly, with the exception of calorie restriction in obese males. However in the other groups, it is possible that although the overall level of HDL did not change the proportion of the $\mathrm{HDL}_{2}$ subfraction may have increased and this is thought to be the specific component providing protection against atherosclerosis [17]. Perhaps the ideal treatment for Type 2 diabetes should achieve good control of the blood glucose, a normal lipid profile and restore the HDL-cholesterol level to normal, specifically the level of $\mathrm{HDL}_{2}$.

Acknowledgements. We thank Dr. B. Northam, the staff of the Department of Clinical Chemistry and Mrs. R. Blackmore of the Dietetic De- partment at the General Hospital, Birmingham, for their help with this project.

\section{References}

1. Davidson MB (1981) The continually changing 'natural history' of diabetes mellitus. J Chron Dis 34: 5-10

2. Tunbridge WMG (1981) Factors contributing to deaths of diabetics under fifty years of age. Lancet 2: 569-572

3. Santen RJ, Willis PW, Fajans SS (1972) Atherosclerosis in diabetes mellitus. Ann Intern Med 130: 833-843

4. Garcia MJ, McNamara PM, Gordon T, Kannel WB (1974) Morbidity and mortality in diabetics in the Framingham population. Sixteen year follow-up study. Diabetes 23: 105-111

5. University Group Diabetes Program (1970) Diabetes 19 suppl 2: $747-830$

6. Kennedy AL, Lappin TRJ, Lavery TD, Hadden DR, Weaver JA, Montgomery DAD (1978) Relation of high-density lipoprotein cholesterol concentration to type of diabetes and its control. $\mathrm{Br}$ Med J 2: 1191-1194

7. Gordon T, Castelli WP, Hjortland MC, Kannel WB, Dawber TR (1977) High density lipoprotein as a protective factor against coronary heart disease. Am J Med 62: 707-714

8. Taylor KG, Wright AD, Carter TJN, Valente AJ, Betts SA, Matthews KA (1981) High-density lipoprotein cholesterol and apolipoprotein AI levels at diagnosis in patients with non-insulin dependent diabetes. Diabetologia 20:535-539

9. Metropolitan Life Insurance Company (1959) Statistical Bulletin 40

10. Carter T, Martin PJ, Wilding P, Goldberg DM (1976) Evaluation of a new kit for serum triglycerides. Clin Chem 22: 520-524

11. Richmond W (1973) Preparation and properties of a cholesterol oxidase from Nocardia sp. and its application to the enzymatic assay of total cholesterol in serum. Clin Chem 19: 1350-1356

12. Burstein M, Scholnick HR, Morfin RJ (1970) Rapid method for the isolation of lipoproteins from human serum by precipitation with polyanions. J Lipid Res 11: 583-595

13. Whitehead TP, Bullock DG, Carter TJN, Moore RA, Penfold W, Johnstone JH, Payne B, Gray SP, Ballantyne SC, Shepherd J, Walker G, McFarlane R, Deegan T (1979) High-density lipoprotein (HDL) cholesterol analysis. Ass Clin Biochem News-sheet 190: $7-10$

14. Bradby GVH, Valente AJ, Walton KW (1978) Serum high-density lipoproteins in peripheral vascular disease. Lancet 2: 1271-1274

15. Kynoch PAM, Lehmann H (1977) Rapid estimation (21/2 hours) of glycosylated haemoglobin for routine purposes. Lancet 2: 16

16. Taylor KG, Carter TJN, Valente AJ, Wright AD, Smith JH, Matthews KA (1981) Sex differences in the relationships between obesity, alcohol consumption and cigarette smoking and serum lipid and apolipoprotein concentrations in a normal population. Atherosclerosis 38: 11-18

17. Gofman JW, Young W, Tandy R (1966) Ischaemic heart disease, atherosclerosis and longevity. Circulation 34: 679-686

Received: 7 January 1982

and in revised form: 5 August 1982

Dr. K.G. Taylor

Department of Diabetes and Endocrinology

Dudley Road Hospital

Dudley Road, Birmingham, B18 7QH, UK 